\title{
OCORRÊNCIA DO LEITE INSTÁVEL NÃO ÁCIDO (LINA) NA REGIÃO NORTE DO MATO GROSSO
}

\section{Occurrence of unstable milk not acid in the north state of Mato Grosso, Brazil}

\author{
Helem Priscilla Martins Souza ${ }^{l}$, Natália Baldasso Romero ${ }^{1 *}$, \\ Claudineli Cássia Bueno da Rosa ${ }^{1}$
}

\section{RESUMO}

Objetivou-se com este estudo, detectar a ocorrência do leite instável não ácido (LINA) na região norte do Mato Grosso, Brasil. Foram analisadas 486 amostras de leite durante os meses de novembro de 2012 a junho de 2013, provenientes de 180 produtores diferentes. Os resultados obtidos apresentaram uma incidência de 13,95\% para o leite LINA, demonstrando que há uma baixa ocorrência, no período em que foram realizadas as coletas.

Palavras-chave: acidez; laticínio; estabilidade.

\begin{abstract}
The objective of this study was to detect the occurrence of unstable nonacid milk (LINA) in the northern region of the state of Mato Grosso, Brazil. A total of 486 milk samples between November/2012 to June/2013, coming from 180 different producers. The results obtained showed an incidence of $13.93 \%$ of LINA milk and revealed a low occurrence when the samples were collected.
\end{abstract}

Keywords: acidity; dairy; stability.

\section{INTRODUÇÃO}

A prova do álcool é um dos testes mais utilizados para avaliar a qualidade do leite produzido e é realizada na propriedade antes do seu carregamento. A prova avalia a estabilidade das proteínas lácteas submetidas à desidratação provocada pelo

1 Universidade Federal do Mato Grosso (UFMT), Campus Sinop, Av. Alexandre Ferronato, 1200, Setor Industrial, 78550-728, Sinop, MT, Brasil. E-mail: natalia_baldasso@hotmail.com.

* Autor para correspondência. 
álcool e é usada para estimar a estabilidade do leite, quando submetido ao tratamento térmico (MARQUES et al., 2007). Esta estabilidade, está diretamente relacionada com a capacidade do leite resistir à coagulação pelo calor e, portanto, às suas características de processamento (SILVA, 2003).

Resultados positivos ao teste do álcool (precipitação) podem ocorrer devido à redução de $\mathrm{pH}$, pela fermentação da lactose até a produção de ácido lático, resultando na instabilidade da proteína (ZANELA et al., 2006). Segundo Fonseca; Santos (2000), microrganismos mesófilos são responsáveis por essa fermentação, que ocorrem em situações de falta de higiene e refrigeração na produção de leite. Marques et al. (2007), citam que resultados positivos podem ser detectados quando houver acidificação do leite devido à presença de culturas bacterianas e, mais recentemente, tem sido descrita a instabilidade da caseína sem relação com acidez elevada. O leite instável não ácido (LINA) é caracterizado pela perda de estabilidade da caseína, resultando em sua precipitação na prova do álcool sem, entretanto, haver acidez acima de $18^{\circ} \mathrm{D}$ (graus Dornic) (MARQUES et al., 2007).

No caso do LINA, este não é influenciado pela elevação da acidez (MARQUES et al., 2007) e também não está associado à perda da estabilidade gerada pela contaminação bacteriana (DONATELE et al., 2003). As causas do leite LINA ainda não são bem esclarecidas. Relata-se a ocorrência de multifatores como causa, tais como, a execução do teste (concentração do álcool), manejo (alimentação, clima, relação homem-animal), ao animal (suscetibilidade ao estresse, potencial produtivo, estádio da lactação, sanidade, problemas digestivos e metabólicos, frações da caseína), entre outros (FISHER et al., 2012).

O leite deve manter um requisito mínimo de estabilidade ao alizarol $72 \%$ para ser aceito pela indústria (BRASIL, 2011) e, portanto, leites que não estão dentro deste padrão acabam sendo descartados. Dessa forma, o leite LINA é confundido com o leite ácido, uma vez que coagula no teste do álcool, gerando prejuízo financeiro na cadeia leiteira, tanto por parte do produtor, quanto por parte da indústria que diminui o potencial de produção. Nos últimos anos, os resultados encontrados em pesquisas mostraram-se preocupantes, devido às altas porcentagens positivas para o leite LINA em regiões de destaque nacional para a produção leiteira (ZANELA et al., 2009; MARQUES et al., 2007; MASCARI et al., 2007). Há também relatos de ocorrências em outros países como Cuba (PONCE; HERNÁNDEZ, 2001) e Uruguai (BARROS et al., 1999).

Sabendo do aumento na produção leiteria nos últimos anos no estado de Mato Grosso (EMBRAPA, 2015) e dos prejuízos causados pelo leite LINA, objetivou-se com este trabalho verificar se há ocorrência do leite instável não ácido na região norte do Mato Grosso.

\section{MATERIAL E MÉTODOS}

No período de novembro de 2012 a junho de 2013, foram coletadas 486 amostras com volume de $200 \mathrm{ml}$ cada, em recipientes de vidro, com tampa. As mesmas foram obtidas dos produtores que fornecem leite para os laticínios dos municípios de Sinop e Lucas do Rio Verde. As coletas foram realizadas nas Unidades de Produção Leiteira (UPL), compreendendo 180 produtores. As amostragens abrangeram os municípios de Sinop, Santa Carmem, Tapurah, Itanhangá, Vera, Sorriso, Nova Mutum, Nova Ubiratã, Ipiranga do Norte e Lucas do Rio Verde.

Após coletadas, as amostras foram acondicionadas em caixas térmicas com gelo e encaminhadas ao laboratório para realização dos testes de estabilidade do leite. As análises foram realizadas no Laboratório de Tecnologia de Alimentos da Universidade 
Federal de Mato Grosso, Campus de Sinop e no Laboratório de análises físico-químicas do laticínio de Lucas do Rio Verde.

O leite foi submetido primeiramente ao teste do álcool (BRASIL, 2006), onde partes iguais $(2 \mathrm{ml})$ de leite e de álcool $72 \%(\mathrm{v} / \mathrm{v})$, foram colocadas em placas de petri, agitados e avaliado quanto à presença de coagulação, considerando como negativas as amostras sem formação de grumos e positiva as amostras com formação de grumos.

As amostras que apresentaram resultados positivos para o teste de álcool foram submetidas ao teste de acidez titulável (Dornic), através da titulação com solução de hidróxido de sódio $0,1 \mathrm{~N}$, usando como indicador uma solução alcoólica de fenoltaleína a 1\% (BRASIL, 2006). Apenas aqueles com a titulação menor ou igual à $18^{\circ}$ Dornic, foram considerados como LINA.

\section{RESULTADOS E DISCUSSÃO}

Os resultados encontrados nas 486 amostras de leite analisadas mostraram que $64,6 \%$ (314) foram estáveis ao álcool 72\% e 35,4\% (172) foram instáveis. Das 172 amostras positivas para o álcool e submetidas ao teste de acidez Dornic, 148 (86,1\%) apresentaram acidez acima de $18^{\circ} \mathrm{D}$ e $24(13,9 \%)$ apresentaram acidez entre $14^{\circ}$ e $18^{\circ} \mathrm{D}$, ou seja, foram considerados leite LINA.

Os resultados do presente estudo demonstraram uma percentagem de ocorrência de LINA inferior, se comparado com os obtidos por Marques et al. (2007), Oliveira et al. (2011) e Zanela et al. (2009). Este fato pode estar relacionado aos meses do ano em que as coletas foram realizadas, novembro a junho, que compreende a estação de chuva, período de melhores condições bioclimatológicas para os animais e de fornecimento de pastagens de melhor qualidade.

Marques et al. (2007) realizaram as coletas durante o período de abril de 2002 a setembro de 2003, na região de Pelotas, no Rio Grande do Sul, e encontraram 58\% de ocorrência de LINA com a maioria das amostras de leite que apresentaram instabilidade à prova do álcool, demonstrando acidez titulável entre 14 e $18^{\circ} \mathrm{D}$. Estes relatam que verificaram influência da época do ano, pois foi obtido uma frequência de leite com problemas de estabilidade ao etanol mais elevada no outono e, provavelmente, deve-se à escassez de alimentos, devido ao fato de que as pastagens de verão estão em fim de ciclo e as de inverno ainda não estão aptas a serem utilizadas. É possível que a partir do mês de agosto e na primavera, a maior disponibilidade de matéria verde das pastagens hibernais e as condições de rebrote do campo nativo, provavelmente, tenham contribuído para menor ocorrência de LINA.

Oliveira et al. (2011), analisaram um total de 451 amostras de leite, fornecidas por produtores da região nordeste do estado de São Paulo, sendo as coletas realizadas em duas épocas do ano, período chuvoso e seco. Foi encontrado um total de $64,8 \%$ de LINA e também uma maior ocorrência no período seco e acredita-se que o fato se deve à combinação entre forragens de baixa qualidade nutricional, devido ao período seco e uso de concentrados de forma desbalanceada. Desequilíbrios energéticos e/ou proteicos da dieta comprometem o metabolismo ruminal e alteram a composição do leite, corroborando com o proposto por Okada et al. (2001) que concluíram que resultados positivos para leite instável não ácido estão associados à insuficiência de nutrientes digestíveis totais fornecidos na dieta.

Zanela et al. (2009) analisaram 2.936 amostras de leite no Rio Grande do Sul, e tiveram ocorrência de 55\% de LINA, também influenciados pela sazonalidade, sendo o final do verão e início do outono, o período mais crítico. Este fator também pode ser evidenciado nos estudos de Ponce; Hernández (2001), onde relatam que a maior presença 
de instabilidade foi verificada nos meses de março e abril, que coincidem com a maior escassez de alimento. Ainda, de acordo com os mesmos autores, amostras alcalinas (acidez inferior a $\left.14^{\circ} \mathrm{D}\right)$ podem ser oriundas de rebanhos com mastite e poderiam ser instáveis ao álcool por causa do processo inflamatório.

A importância na disponibilidade e qualidade do alimento fornecido durante o ano aos animais, está diretamente ligado à quantia e qualidade do leite produzido. Este fato pode ser evidenciado no estudo de Zanella et al. (2006), onde submeteram quatro vacas da raça Jersey a uma dieta de $60 \%$ da exigência nutricional e outras quatro vacas da mesma raça para controle com a alimentação de $100 \%$ da exigência nutricional diária. Estes animais foram alimentados em duas etapas, sendo a primeira de 18 e a segunda de 19 dias, confirmando que a restrição alimentar de $40 \%$ em animais da raça Jersey aumenta a incidência de LINA.

Ponce; Hernández (2001) relataram ainda que as limitações de energia disponíveis no tecido epitelial mamário afetam a síntese e secreção dos componentes lácteos, levando à instabilidade. As causas da instabilidade do leite ainda não estão bem esclarecidas. Existem diferentes estudos e indicações, como por exemplo, no estudo de Barros et al. (1999) (1999) onde relata que as variações na estabilidade do leite têm sido relacionadas a dietas ou pastos ricos em cálcio, com deficiências ou desequilíbrios minerais $(\mathrm{Ca}, \mathrm{P}$, $\mathrm{Mg}$ ) e a mudanças bruscas da dieta. Veloso (1998) cita que silagens com elevado teor de fibra e excesso de concentrados proteicos são fatores capazes de alterar o equilíbrio cálcio-magnésio e ocasionar reações positivas à prova do álcool. Porém, os dados apresentados demonstram a relevância do fator sazonal na ocorrência de LINA, tanto pela geração do estresse térmico, quanto pela diminuição da oferta de forragem.

Oliveira et al. (2011) citam que diante dos resultados encontrados, observa-se que grande parte do leite coletado poderia ser erroneamente classificada como ácido, o que levaria consequentemente a prejuízos econômicos tanto ao produtor quanto à indústria, devido à rejeição ou subvalorização do produto, mesmo com os níveis de acidez considerados normais pelos padrões estabelecidos pelo Ministério da Agricultura. Marques et al. (2007) concluíram que o leite LINA afeta a composição química do leite, com diminuição dos teores de proteína e lactose, mas com aumento do teor de gordura. No entanto, a maior parte do leite instável não é ácida, nem altera de forma expressiva a composição química do leite, que apresenta valores considerados normais. Oliveira et al (2007), reforça que apesar de também terem encontrado mudanças na composição química do leite não há justificativa para a rejeição do leite instável não ácido pelas indústrias ou a penalização dos produtores que fornecerem este tipo de produto, pois todos os valores de composição obtidos são considerados normais para animais criados em regime de pastejo, sendo necessário que se estabeleça regras para que as indústrias evitem estas distorções.

\section{CONCLUSÕES}

Conclui-se que há presença de leite instável não ácido (LINA) na região médionorte do Mato Grosso, porém, com baixa incidência quando comparada a outros estudos, podendo os valores ter sido afetados pela época do ano.

\section{REFERÊNCIAS}

BARROS, L. et al. Prueba del alcohol em leche y relación com calcio iónico. Revista Prácticas Veterinarias, v. 9, p. 315-318, 1999.

BRASIL. Ministério da Agricultura, Pecuária e Abastecimento. Instrução Normativa $n^{\circ} 62$, de 29 de dezembro de 2011. Aprova o Regulamento 
Técnico de Produção, Identidade e Qualidade do Leite tipo A, o Regulamento Técnico de Identidade e Qualidade de Leite Cru Refrigerado, o Regulamento Técnico de Identidade e Qualidade de Leite Pasteurizado e o Regulamento Técnico da Coleta de Leite Cru Refrigerado e seu Transporte a Granel, em conformidade com os Anexos desta Instrução Normativa. Diário Oficial da República Federativa do Brasil, Brasília, 30 dez. 2011. Seção 1, p. 6.

BRASIL. Ministério da Agricultura, Pecuária e Abastecimento. Instrução Normativa $n^{\circ} 68$, de 12 de dezembro de 2006. Oficializa os métodos analíticos oficiais físico-químicos, para controle de leite e produtos lácteos. Diário Oficial da República Federativa do Brasil, Brasília, 14 dez. 2006. Seção 1, p. 8.

DONATELE, D. M. et al. Relação do teste de alizarol a $72 \%(\mathrm{v} / \mathrm{v})$ em leite in natura de vaca com acidez e contagem de células somáticas: análise microbiológica. Higiene Alimentar, v. 17, p. 95-100, 2003.

EMPRESA BRASILEIRA DE PESQUISA AGROPECUÁRIA (EMBRAPA). Panorama do Leite. 2015. Disponível em: <https://www. embrapa.br/documents/1355117/1528925/ Panorama+do+Leite+-+outubro+2015/ f97da482-483f-4451-bd26-e9f7e1d95c4b>. Acesso em: 21 jun. 2016.

FISCHER, V. et al. Leite instável não ácido: um problema solucionável? Revista Brasileira de Saúde e Produção Animal, v. 13, n. 3, p. 838-849, 2012.

FONSECA, L. F. L. DA; SANTOS, M. V. DOS. Qualidade do leite e controle da mastite. São Paulo: Lemos, 2000. 175p.

MARQUES, L. T. et al. Ocorrência do leite instável ao álcool 76\% e não ácido (LINA) e efeitos sobre os aspectos físico-químicos do leite. Revista Brasileira Agrociência, v. 13, n. 1, p. 91-97, 2007.

MASCARI, F. B. et al. 2007. Incidência de leite instável não-ácido (LINA) recebido em laticínio do Estado de São Paulo. In: Simpósio Internacional de Iniciação Cientifica e Tecnológica da USP (SIICUSP), São Paulo. Anais eletrônicos... Disponível em: $<$ https:// uspdigital.usp.br/siicusp/cdOnlineTrabalho VisualizarResumo?numeroInscricao Trabalho $=3906 \&$ numeroEdicao $=16>$. Acesso em: 21 jun. 2016.

OKADA, K. et al. Changes in quantity, componentes and properties of postpartum milk in Japanese black cows. Journal of Japanese Veterinary Association, v. 54, p. 185-190, 2001.

OLIVEIRA, C. A. F. et al. Composição e características físico-químicas do leite instável não ácido recebido em laticínio do Estado de São Paulo, Brasil. Revista Brasileira de Saúde e Produção Animal, v. 12, n. 2, p. 508-515, 2011.

PONCE, P.; HERNÁNDEZ, R. Propriedades físico-químicas do leite e sua associação com transtornos metabólicos e alterações na glândula mamária. In: GONZÁLEZ, F. H. D. et al. Uso do leite para monitorar a nutrição e o metabolismo de vacas leiteiras. Porto Alegre: UFRGS, 2001. p. 61-72.

SILVA, P. H. F. Leite UHT: fatores determinantes para sedimentação e gelificação. 2003. 147f. Tese (Doutorado em Ciências dos Alimentos) - Universidade Federal de Lavras, Lavras, 2003.

VELLOSO, C. R. V. Noções básicas da acidez. In: BRITO, J. R. F.; DIAS, J. C. A qualidade do leite. São Paulo: Tortuga, 1998. p. 37-45.

ZANELA, M. B. et al. Leite instável não-ácido e composição do leite de vacas Jersey sob restrição alimentar. Pesquisa Agropecuária Brasileira, v. 41, n. 5, p. 835-840, 2006.

ZANELA, M. B. et al. Ocorrência do leite instável não ácido no noroeste do Rio Grande do Sul. Arquivo Brasileiro de Medicina Veterinária e Zootecnia, v. 61, n. 4, p. 1009-1013, 2009. 